\section{Commentary: Location is not everything: Transseptal valve-in-valve in intra-arterially implanted mitral prostheses}

\author{
Gabriel Georges, MD, \\ Dimitri Kalavrouziotis, MD, FRCSC, and \\ Siamak Mohammadi, MD, FRCSC
}

Mitral annular calcification (MAC) is a challenge in patients requiring mitral valve intervention. MAC is associated with poor outcomes after mitral valve surgery, ${ }^{1}$ and there is no optimal surgical management strategy. The calcified annulus can be approached by decalcification combined with annular reconstruction ("resect strategy") or by avoiding annular decalcification ("respect strategy"). Decalcification can allow for superior seating of the prosthesis and has a lower risk of paravalvular regurgitation. However, this comes at the cost of an increased risk of catastrophic atrioventricular-groove disruption, injury to the circumflex artery, and thromboembolic events. Decalcification also requires longer crossclamp and cardiopulmonary bypass times and is often regarded as the more technically challenging option. ${ }^{2}$ In patients with circumferential MAC, a more conservative "respect strategy" may be employed as a bailout procedure. A rarely used technique is to implant the prosthesis by sewing it into the atrial wall. Intra-atrial mitral prosthesis implantation was initially described by Nataf and colleagues ${ }^{3}$ in 1994 using a Dacron collar to enlarge the sewing ring of the prosthesis. Similar techniques are also described. ${ }^{4,5}$

\footnotetext{
From the Department of Cardiac Surgery, Quebec Heart and Lung Institute, Quebec City, Quebec, Canada.

Disclosures: The authors reported no conflicts of interest.

The Journal policy requires editors and reviewers to disclose conflicts of interest and to decline handling or reviewing manuscripts for which they may have a conflict of interest. The editors and reviewers of this article have no conflicts of interest.

Received for publication Aug 31, 2021; revisions received Aug 31, 2021; accepted for publication Sept 2, 2021; available ahead of print Sept 17, 2021.

Address for reprints: Siamak Mohammadi, MD, FRCSC, Department of Cardiac Surgery, Quebec Heart and Lung Institute, 2725 chemin Sainte-Foy, Quebec City, Quebec, Canada, G1V 4G5 (E-mail: siamak.mohammadi@fmed.ulaval.ca).

JTCVS Techniques 2021;10:273-4

2666-2507

Copyright (c) 2021 The Author(s). Published by Elsevier Inc. on behalf of The American Association for Thoracic Surgery. This is an open access article under the CC BY-NC-ND license (http://creativecommons.org/licenses/by-nc-nd/4.0/)

https://doi.org/10.1016/j.xjtc.2021.09.006
}

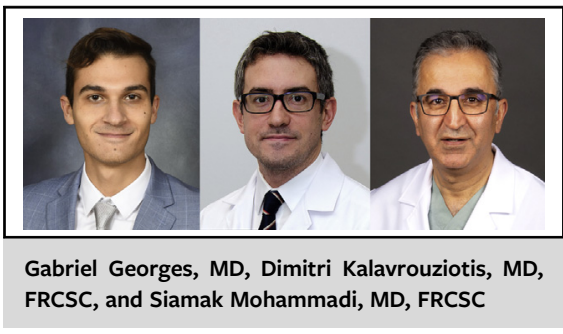

\author{
CENTRAL MESSAGE \\ Transseptal transcatheter mitral \\ valve-in-valve replacement is a \\ viable option in patients with a \\ mitral valve prosthesis in an intra- \\ atrial position.
}

In this issue of the Journal, Falasa and colleagues ${ }^{6}$ report the case of an 80-year-old woman with a high surgical risk who presented with congestive heart failure due to degenerative bioprosthetic mitral valve stenosis. Eight years earlier, the patient's initial mitral valve replacement was performed using a 25-mm Carpentier-Edwards bovine pericardial prosthesis in an intra-atrial position. Falasa and colleagues performed a transseptal transcatheter mitral valve-in-valve (TMViV) replacement despite the anomalous position of the valve. To summarize, 3-dimensional transesophageal echocardiography-guided septal puncture was performed $2 \mathrm{~cm}$ above the plane of the valve, and a SAPIEN 3 valve was deployed within the mitral prosthesis via standard alignment techniques. Postdeployment echocardiography showed satisfactory prosthesis function. The authors concluded that intra-atrial placement of a bioprosthetic mitral valve does not preclude TMViV replacement.

Successful TMViV replacement using balloonexpandable bioprostheses has been previously reported. ${ }^{7}$ However, whether these results can be reproducible in mitral bioprostheses that have been intra-arterially implanted is unknown. The case report by Falasa and colleagues ${ }^{6}$ suggests that intra-atrial suturing of a mitral prosthesis due to severe MAC is not a contraindication to future TMViV replacement, and that such a strategy remains a viable option for patients with MAC, as firstintention transcatheter mitral valve replacement platforms continue to be investigated. ${ }^{8}$ The case reported by Falasa and colleagues is well described ${ }^{6}$ and highlights the importance of pre- and intraoperative imaging. A transfemoral transseptal approach may be the preferred approach among patients with intra-atrial mitral bioprosthetic implantation, 
in whom the valve position is closer to the intra-atrial septum, compared with a more-invasive transapical approach.

\section{References}

1. Fox CS, Vasan RS, Parise H, Levy D, O'Donnell CJ, D'agostino RB, et al. Mitral annular calcification predicts cardiovascular morbidity and mortality: the Framingham Heart Study. Circulation. 2003;107:1492-6.

2. Bedeir K, Kaneko T, Aranki S. Current and evolving strategies in the management of severe mitral annular calcification. J Thorac Cardiovasc Surg. 2019;157: 555-66.

3. Nataf P, Pavie A, Jault F, Bors V, Cabrol C, Gandjbakhch I. Intraatrial insertion of a mitral prosthesis in a destroyed or calcified mitral annulus. Ann Thorac Surg. 1994;58:163-7.
4. Atoui R, Lash V, Mohammadi S, Cecere R. Intra-atrial implantation of a mitral valve prosthesis in a heavily calcified mitral annulus. Eur J Cardiothorac Surg. 2009;36:776-8.

5. Santana O, Lamelas J. Intra-atrial placement of a mitral prosthesis in a patient with severe mitral annulus calcification: a case report. Heart Surg Forum. 2010;13:1-4.

6. Falasa MP, Tartara P, Matar R, Jones TE, Anderson RD, Beaver TM. Transseptal mitral valve-in-valve replacement of intra-atrial mitral prosthesis in a patient with severe mitral annular calcification. J Thorac Cardiovasc Surg Tech. 2021;10: 266-8.

7. Yoon SH, Whisenant BK, Bleiziffer S, Degaldo V, Schofer N, Eschenbach L, et al. Transcatheter mitral valve replacement for degenerated bioprosthetic valves and failed annuloplasty rings. J Am Coll Cardiol. 2017;70:1121-31.

8. Hensey M, Brown RA, Lal S, Sathananthan J, Ye J, Cheung A, et al. Transcatheter mitral valve replacement: an update on current techniques, technologies, and future directions. JACC Cardiovasc Interv. 2021;14:489-500. 